\title{
Analysis of Advantages, Benefits and Strategies of the Development of Kiwifruit Industry in Sichuan Cangxi County
}

\author{
Xin Wang \\ School of Economics \& Management, University of Sichuan Agriculture \\ 555 Southeast Road, Wenjiang, Chengdu 611130, China \\ E-mail: nicholivan@163.com \\ Wenkuan Chen (Corresponding author) \\ School of Economics \& Management, University of Sichuan Agriculture \\ 555 Southeast Road, Wenjiang, Chengdu 611130, China \\ E-mail: cwk9889@yahoo.com.cn
}

Song Liu

School of Economics \& Management, University of Sichuan Agriculture 555 Southeast Road, Wenjiang, Chengdu 611130, China

E-mail: songliu1987@163.com

Received: June 13, 2011

Accepted: July 18, $2011 \quad$ Published: December 1, 2011

doi:10.5539/ijbm.v6n12p286

URL: http://dx.doi.org/10.5539/ijbm.v6n12p286

The research is financed by Sponsors: Modern ecological agriculture planning in Southwest (CR1002)

\begin{abstract}
The "Agriculture, Countryside and Farmer" issues are an important content related to the country's overall strategy, and to develop characteristic agriculture is the fundamental way to solve the "Agriculture, Countryside and Farmer" issues. The Hongyang kiwifruit industry in Cangxi County of Sichuan Province has played an important role in increasing farmers' income, optimizing the agricultural structure and promoting the rural development. Based on analyzing the comparative advantages, costs and benefits of the Hongyang kiwifruit industry development in Cangxi County, this article proposes to rely on science and technology, innovation mechanism, implementation of brand strategy and other strategies to promote the Hongyang kiwifruit industry development in Cangxi County.
\end{abstract}

Keywords: Characteristic agriculture, Industry development, Comparative advantages, Costs and benefits

\section{Introduction}

With China's economic and social development, the "Agriculture, Countryside and Farmer" issues have become increasingly prominent, and have also become the important "bottleneck" affecting the coordinated and sustainable development of China's economy and society (Xue Liang, 2008). Therefore, both the governments at all levels and many scholars are very concerned about the "Agriculture, Countryside and Farmer" issues. Since 2004, the Central Committee of the Communist Party of China and the State Council focused on how to make efforts to solve the "Agriculture, Countryside and Farmer" issues in seven consecutive "No.1 Document". The key to the "Agriculture, Countryside and Farmer" issues is the issue of farmers, the core of which is the issue of income, so to increase the farmers' income is an effective way to solve the "Agriculture, Countryside and Farmer" issues. With the opportunity for China to continue to carry out the West Development strategy, the west should increase the intensity of developing characteristic agriculture, and give priority to the development of economic crops which can bring high benefits to farmers, which is directly related to increasing the farmers' income (Lan Xq, 2009).

The kiwifruit industry is one of the characteristic and efficient agricultures, and its role in adjusting the agricultural structure and increasing the farmers' income is obvious. According to the survey, nearly 100 counties 
(cities, districts) in Sichuan Province have planted or are preparing to plang kiwifruit, with the development trend being good. By the end of 2009, the kiwifruit planting area in Sichuan Cangxi County alone reached 105 thousand acres, with the production of $35 \mathrm{kt}$, and it has become the origin of Hongyang kiwifruit, known as China's No.1 red flesh kiwifruit county and Sichuan's characteristic agriculture (kiwifruit) base county. Therefore, to strengthen the study on the development of local characteristic agriculture is conducive to promoting the in-depth development of characteristic agriculture, increasing the farmers' income and making the countryside harmonious.

\section{Status and Experience of Kiwifruit Industry Development in Sichuan Cangxi}

\subsection{Status of Kiwifruit Industry Development in Sichuan Cangxi}

Cangxi County began the kiwifruit resource census since 1978, made introduction and cultivation experiments in 1981, and at the same period, started to select seed and breed. Due to the unique soil, climate and other ecological systems, Cangxi is recognized by experts as the best suitable area for kiwifruit, and in 1983, kiwifruit was planted in Dongxi, Yonghe, Gaopo and other four towns in large areas (about 35 acres in total). The cultivated variety is based on Chuanmi No.1, No.2, No.3 and No.4, which are mainly taken as plant materials. In 1988, the Cangxi County Kiwifruit Food and Beverage Plant, and developed the kiwifruit juice concentrate, beverage, wine, salads and other processing varieties, with the products in short supply. Because of high economic benefits and driven by processing enterprises, the year 1990 saw the artificial plantation peak, and 26 kiwifruit base towns were established in the whole county, with the planting area up to 80 acres and the production reaching $20 \mathrm{kt}$, besides, the kiwifruit beverage plants and the canned food plants in the county purchased and processed more than 10kt of fresh kiwifruit annually. The county's planting area, production, processing product development, seed selection and breeding as well as the scientific and technological achievements rank the first in China. Since 1994, the variety structure has been greatly adjusted, changing from mainly cultivating the processing varieties in the past to mainly cultivating the fresh-sold varieties. In 2002, Sichuan Scientific Institute of Natural Resources together with Cangxi scientists successfully selected and cultivated the fine Hongyang kiwifruit variety to vigorously promote and develop, and organized fruit growers to produce by strictly following China's standards for green food and "export record", so in 2004, the fruit was identified as "protected origin product", and in 2006, Cangxi County was identified by China General Chamber of Commerce (CGCC) as "China's safe and healthy food supply base" and was named by China National Food Industry Association (CNFIA) as "China's No.1 red flesh kiwifruit county". By the end of 2009, the kiwifruit planting area in Cangxi County reached 105 acres, with the product of $35 \mathrm{kt}$, and thereinto, the planting area of Hongyang kiwifruit totaled 80 acres, with the production up to $25 \mathrm{kt}$. The kiwifruit industry in Cangxi County has played an important role in promoting the county's economy and increasing farmers' income.

\subsection{Successful Experience of Developing Kiwifruit Industry in Sichuan Cangxi}

With the gradually flowing sales channels for kiwifruit exports in recent years, the kiwifruit industry has developed rapidly and has become a major pillar industry of the rural economy in Cangxi County, and it has made a positive contribution to pormoting farmers' income increase and improving the ecological environment. In order to promote the development of kiwifruit industry, Cangxi County has mainly taken the following measures.

\subsubsection{Taking Market Demand as Orientation to Exert Great Efforts to Develop International Kiwifruit Market}

The kiwifruit production in the world mainly depends on the export market, thereby being able to gain maximal production profits. The export volume for fresh kiwifruit in the world has been in steady growth in the first 5 years of 21 st century, and has reached $68.8 \%$ of the total kiwifruit production, with the demand being brisk. The average import and export prices for fresh kiwifruit in the world have gradually picked up in recent years, and the average export price for kiwifruit in the world was nearly $\$ 1,000 /$ ton, while the average import price was about $\$ 1,200 /$ ton. The average unit export price for kiwifruit from New Zealand was the highest at $\$ 1,090.49 /$ ton . In 2009, the production of fresh kiwifruit was $35.7 \mathrm{kt}$ in the whole county, and the kiwifruit was exported to 21 countries and regions including EU, Southeast Asia, Chinese Hongkong and Taiwan as well as some big and medium cities in China, becoming one of China's kiwifruit production and export bases. Therefore, it completed the Cangxi kiwifruit export base records and opened the channel to the international market.

2.2.2 Taking Government as the Promoter and Enterprises as the Puller to Strive to Form the Large-scale Development of Kiwifruit Industry

Since 1978, the Cangxi County Committee and Government has changed seven times, but the change in government and the replacement of leadership did not change the characteristic kiwifruit industry, and the government set up the kiwifruit industry office, creating another industry leader of modern characteristic agriculture after the "Cangxi pear". Driven by Hong Kong Risheng Agriculture (Development) Co., Ltd., Cangxi Hengrun Agriculture Co., Ltd., Sichuan Yili Kiwi Fruit Industry Co., Ltd., Cangxi County Kiwifruit Food Co., 
Ltd. and many other leading enterprises, the majority of kiwifruit growers have been successfully linked closely, and a fast track from the fruit farms to the international high-end kiwifruit market was built, thereby providing a guarantee for the industry development and market risk control, so as to ensure growers' brisk production momentum. The whole county also established 24 cooling low-ethylene storages and 2 kiwifruit deep-processing enterprises.

2.2.3 Taking Modern Technology as the Support to Actively Build the Quality Assurance System for Kiwifruit Industry Development

As to the scientific and technological achievements, the standardized modern kiwifruit farm-building technologies researched and developed by Cangxi County include the soil improvement with ridge box, mechanized operations and the comprehensive treatment technology, and they have been successfully promoted and applied in large areas in the whole county. The application of the researched and developed conservation-oriented bedpost and plastic covered steel frame materials has reduced the cost of scaffolding. The researched and developed fruit-bagged technology, bio-organic fertilizer application and pollution-free pesticide residue control technology have been promoted and applied in large areas in the whole county. As to the industrial promotion system, four representative integration models of production, teaching and research have been initially formed, including the enterprise driving model, the cooperative driving model, the science and technology driving model as well as the small-owner and large-park model. As to the kiwifruit technical service system, Cangxi County has already built the primary technical service network which takes the kiwifruit industry office and the institute as the center, the town technicians as the main line, and the professional farmer cooperative as the carrier in the new situation. Cangxi kiwifruit enjoys high popularity at home and abroad, and it is a member of the commonwealth of Actinidia chinensis. The fresh kiwifruit and its processed products have passed the national green food demonstration one after another. Cangxi kiwifruit has won the national protection of origin, and the kiwifruit planting areas have been identified as the state-level kiwifruit standardized demonstration area.

\section{Analysis of Cangxi's Advantages for Kiwifruit Development}

\subsection{Good Ecological Environment and Climate Resources}

Cangxi County is located in the mountainous area of northern Sichuan Basin, and the North is low mountains and narrow valleys with the general altitude of 700-1,000 meters, accounting for $35.2 \%$ of the total area, while the forest coverage is $48 \%$; the Northeast is the Changliang Platform with low mountains and valleys, and the general altitude is $600-800$ meters, accounting for $29 \%$ of the total area; the South is deep hills and medium valleys, and the general altitude is $400-700$ meters, accounting for $35.8 \%$ of the total area. The parent material in the whole county is the Cretaceous purple shale, and the soil is the brown-purple clay and yellow-reddish clay. The annual precipitation is $1,046.7 \mathrm{~mm}$ and the mean temperature is $16.7^{\circ} \mathrm{C}$, and the annual sunshine duration is $1,490.9$ hours, while the frost-free period is 288 days. Within the county, there are many rivers and streams, so it is suitable for both kiwifruit growth and large-scale planting. Cangxi Hongyang kiwifruit gets mature in September, while the New Zealand kiwifruit which accounts for more than a quarter of the world's kiwifruit export market share becomes mature in May, therefore, the industrialized development has the advantage of time difference from the main producing country in the world. Meanwhile, it adapts to the cultivation in the relatively humid regions in Sichuan hills and the mountainous regions around the basin, and practices have proven that the region belongs to the high-efficiency ecological economic forest in returning farmland to forest, so it also allows the strip intercropping of bamboo and fruit, which is of an important role for soil and water conservation.

\subsection{Fine Variety Resources}

Hongyang kiwifruit is a fruit that consumers are deeply fond of, and the main reasons are that the fruit is tender and juicy, delicious and fresh, sweet, sour and pleasant, extremely nutritious, the soluble solids content is $19.6 \%$, $13.45 \%$ of sugar, $0.49 \%$ of total acid, $135.77 \mathrm{mg} / 100 \mathrm{~g}$ of $\mathrm{VC}$, and the sugar to acid ratio is $27.45: 1$, besides, it also contains large amounts of protein, amino acids and many other organic compounds as well a variety of essential minerals for human body. According to the test made by the Food Research Center of the American Rutgers University, kiwifruit is the fruit with most abundant and comprehensive nutrients (LV JH,2009). Cangxi is the birthplace of Hongyang kiwifruit, and the selected and bred Hongyang kiwifruit won the advanced science and technology award of Sichuan Province and the new variety promoted by the Provincial Agriculture and Animal Husbandry Department, besides, in 2005, it won the national protected new variety, being the unique rare variety in the world. Hongyang kiwifruit has strong market competitiveness and development potential.

\section{Comparative Analysis of Costs and Benefits of Hongyang Kiwifruit, Pear and the Sichuan Planting Patterns in Cangxi County}

\subsection{Comparative Analysis of Production Costs}

Different economic crops and different planting patterns will result in different incomes, so their costs will vary. 
Hereby, this article compares the production costs of Hongyang kiwifruit, Cangxi pear and four kinds of grain planting patterns (the inputs do not include the infrastructure such as roads, drainages and irrigation facilities and so on, each laborer is 50 yuan/day, the production materials all calculated according to the commodity prices in 2009, and the production costs do not include the cost of land).

\subsubsection{Production Cost Structure and Comparison of Hongyang Kiwifruit and Cangxi Pear}

The costs of Hongyang kiwifruit and Cangxi pear in the construction period are: the construction period of Hongyang kiwifruit is 3 years, with the total investment being 8,585 yuan/acre (including the mechanical soil improvement, fertilizer, manure, seedling, bedpost, wiring, laborers and all the other farm-building costs as well as the costs of laborer management, fertilizer, pesticides and other materials in the first 3 years after being put into production). The construction period of Cangxi pear is 4 years, with the total investment being 5,810 yuan/acre (including the soil improvement, fertilizer, manure, seedling, laborers and all the other farm-building costs as well as the costs of laborer management, fertilizer, pesticides and other materials in the first 4 years after being put into production). The economic lives of Hongyang kiwifruit and Cangxi pear trees are both 20 years, and if to allocate the investments into the construction periods of Hongyang kiwifruit (the first 3 years) and Cangxi pear (the first 4 years) to the 20 years after being put into production, the annual amortized costs of Hongyang kiwifruit and Cangxi pear are respectively $6,448.8$ yuan $/ \mathrm{hm}^{2}$ and $4,357.5 \mathrm{yuan} / \mathrm{hm}^{2}$. The basic costs of Hongyang kiwifruit and Cangxi pear in the year of being put into production are: the annual cost of laborer management of Hongyang kiwifruit is 1,100 yuan/acre, and the material cost is 1,170 yuan/acre, thus the total cost is 2,270 yuan/acre, that is, 34,050 yuan $/ \mathrm{hm}^{2}$. The annual cost of laborer management of Cangxi pear is 800 yuan/acre, and the material cost is 970 yuan/acre, thus the total cost is 1,770 yuan/acre, that is, $26,550 \mathrm{yuan} / \mathrm{hm}^{2}$. The costs of laborer management of the above two kinds of fruit trees both include fertilizing, weeding, disease prevention and pest control, bagging, management and protection, picking and all the other labor costs, and the material costs of the two both include fertilizers, pesticides, water and all the other material costs. After being put into production, the total cost in each year is the amortized costs in the construction period plus the costs in the year of being into production. Therefore, the total production costs of Hongyang kiwifruit and Cangxi pear are respectively $40,488.8$ yuan $/ \mathrm{hm}^{2}$ and $30,907.5$ yuan $/ \mathrm{hm}^{2}$ per year, and the production cost of Hongyang kiwifruit is higher than that of Cangxi pear.

\subsubsection{Analysis of the Cost Structure of Four Planting Patterns of Grain and Oil Crop Combination}

The four planting patterns of grain and oil crop combination are respectively "rice + wheat", "wheat + corn + sweet potato", "wheat + corn + peanut" and "rice + rape", and their costs are different (see Table 1). From the perspective of absolute number, the costs of the four planting patterns are all at above $20,000 \mathrm{yuan} / \mathrm{hm}^{2}$, and the cost of planting pattern 3 is the highest, followed by planting pattern 2 and planting pattern 1, while the cost of planting pattern 4 is the lowest, and they are respectively 31,830 yuan $/ \mathrm{hm}^{2}, 26,820$ yuan $/ \mathrm{hm}^{2}, 22,800 \mathrm{yuan} / \mathrm{hm}^{2}$ and $22,575 \mathrm{yuan} / \mathrm{hm}^{2}$. From the perspective of relative number, the labor costs of the four planting patterns all account for high proportions of above $60 \%$; thereinto, the labor cost of planting pattern 2 accounts for the highest proportion of $71 \%$, followed by that of planting pattern 3 at $67 \%$, while the labor costs of planting pattern 1 and planting pattern 4 both account for a proportion of $62 \%$.

\subsection{Comparison of Total Income and Total Profits}

Through investigating, collecting and sorting, summing up and calculating the planting situation and the industry development, it concludes that: the average production of Hongyang kiwifruit is $15,000 \mathrm{~kg} / \mathrm{hm}^{2}$, and the average unit price in the market is 11.00 yuan $/ \mathrm{kg}$, thus the income is converted into $165,000 \mathrm{yuan} / \mathrm{hm}^{2}$. The average production of Cangxi pear is $37,500 \mathrm{~kg} / \mathrm{hm}^{2}$, and the average unit price in the market is $1.00 \mathrm{yuan} / \mathrm{kg}$, thus the income is converted into 375,000 yuan $/ \mathrm{hm}^{2}$. As to the four planting patterns composed of 5 kinds of grains, the average market price for the rice is 1.9 yuan $/ \mathrm{kg}$, the corn is 1.7 yuan $/ \mathrm{kg}$, the wheat is 1.84 yuan $/ \mathrm{kg}$, the sweet potato is 0.4 yuan $/ \mathrm{kg}$, the peanut is 4.4 yuan $/ \mathrm{kg}$ and the rape is 1.8 yuan $/ \mathrm{kg}$. As to planting pattern 1 , the average rice production is $9,375 \mathrm{~kg} / \mathrm{hm}^{2}$, and the income is $17,812.5 \mathrm{yuan} / \mathrm{hm}^{2}$; the average wheat production is $4,875 \mathrm{~kg} / \mathrm{hm}^{2}$, and the income is 8,970 yuan $/ \mathrm{hm}^{2}$; thus the total income is $26,782.5 \mathrm{yuan} / \mathrm{hm}^{2}$. As to planting pattern 2, the average wheat production is $2,625 \mathrm{~kg} / \mathrm{hm}^{2}$, and the income is $4,830 \mathrm{yuan} / \mathrm{hm}^{2}$; the average corn production is $6,750 \mathrm{~kg} / \mathrm{hm}^{2}$, and the income is $11,475 \mathrm{yuan} / \mathrm{hm}^{2}$; the average sweet potato production is $4,500 \mathrm{~kg} / \mathrm{hm}^{2}$, and the income is $1,800 \mathrm{yuan} / \mathrm{hm}^{2}$; thus the total income is $18,105 \mathrm{yuan} / \mathrm{hm}^{2}$. As to planting pattern 3 , the average wheat production is $2,625 \mathrm{~kg} / \mathrm{hm}^{2}$, and the income is $4,830 \mathrm{yuan} / \mathrm{hm}^{2}$; the average corn production is $6,750 \mathrm{~kg} / \mathrm{hm}^{2}$, and the income is $11,475 \mathrm{yuan} / \mathrm{hm}^{2}$; the average peanut production is $2,250 \mathrm{~kg} / \mathrm{hm}^{2}$, and the income is 9,900 yuan $/ \mathrm{hm}^{2}$; thus the total income is 26,205 yuan $/ \mathrm{hm}^{2}$. As to planting pattern 4 , the average rice production is $9,750 \mathrm{~kg} / \mathrm{hm}^{2}$, and the income is $18,525 \mathrm{yuan} / \mathrm{hm}^{2}$; the average rape production is $2,250 \mathrm{~kg} / \mathrm{hm}^{2}$, and the income is 8,100 yuan $/ \mathrm{hm}^{2}$; thus the total income is $26,625 \mathrm{yuan} / \mathrm{hm}^{2}$.

According to the formula of "total profit = total income - total cost", it is calculated that: the total profits of 
Hongyang kiwifruit and Cangxi pear are respectively 124,511.2 yuan $/ \mathrm{hm}^{2}$ and $6,592.5 \mathrm{yuan} / \mathrm{hm}^{2}$, and the total profits of planting pattern 1,2, 3 and 4 are respectively $3,982.5$ yuan $/ \mathrm{hm}^{2},-8,715$ yuan $/ \mathrm{hm}^{2},-5,625 \mathrm{yuan} / \mathrm{hm}^{2}$ and 4,050 yuan $/ \mathrm{hm}^{2}$ (see Table 2 for details). Therefore, the benefit of planting Hongyang kiwifruit is much higher than other planting models.

\section{Strategies to Promote the Development of Hongyang Kiwifruit Industry in Cangxi}

\subsection{Relying on Science and Technology to Vigorously Promote the Large-scale and Standardized Production}

After China's accession to WTO, the international and domestic markets have provided broad space for new development. Therefore, it requires to carefully study how to position the Hongyang kiwifruit industry in Cangxi from the strategy perspective, and it requires to make planning in line with the market demand as well as the development conditions of local and surrounding areas, thus to clarify goals, determine the scale, prepare detailed development strategies and put forward practical development plans. The focuses are the standardized production in bases, storage, preservation, transportation and the extension of processing chain, and it should plan, demonstrate, package and win over projects by encircling these stages, so as to have access to policy support and multi-channel financial support(Chen Wk, 2003).

Specifically, the work in the following four aspects should be well done: the first is the rational distribution. The distribution should highlight the variety characteristics and the best production areas, thus to plant Hongyang kiwifruit in the best ecological areas according to its biological characteristics. The second is the scale operation. The operation should be policy-oriented, and takes the measures of investment tilting and administrative promotion, so as to promoting the scale development of the industry in advantageous areas. The third is to formulate and enact the technical standards for Hongyang kiwifruit production. This can make the production, processing, product sales and processing sectors be pollution-free, and make the products reach the standard for green food, thus to accelerate the adoption of international rules and standards and enhance the market competitiveness. The fourth is to increase the scientific research on kiwifruit. It should widely introduce kiwifruit experts and management personnel, and based on increasing the investment into the Cangxi kiwifruit institute, it should widely conduct institute-institute cooperation, institute-enterprise cooperation and establish the kiwifruit talent tank, so as to solve the technical difficulties appearing in Hongyang kiwifruit production to make focused and purposeful technological breakthrough, providing the scientific and technological supports for the healthy development of kiwifruit industry.

\subsection{Innovating Mechanisms to Actively Introduce and Cultivate Leading Enterprises}

During the evolution of industrialized management of Hongyang kiwifruit, the professional cooperative organizations and leading enterprises become two indispensable wheels, and the scale distribution reduces the intermediate links for farmers to enter into the market, thus the marketing costs have been greatly decreased. There exists the game of interest between farmers and the professional cooperative organizations or leading enterprises that are both the market players. Therefore, the benefit-linking mechanism should be well constructed to make Hongyang kiwifruit industry become bigger and stronger, and this will make farmers and leading enterprises become the market players that are resistant to market risks. It should further study farmers' sharing of the follow-up profits in the processing and sales stages, and establish the risk fund for the development of kiwifruit industry, so as to relieve farmers' troubles back at home and make it gain sustainable development. The specific requirements are: the first is to give full play to the market's basic role of allocating resources, so that the professional cooperative organizations and processing enterprises can drive the whole industry. The second is that the government should strengthen services, pay attention to guiding and forming the consensus that "to support industrialization is to support agriculture, and to support leading enterprises is to support farmers", and make good, flexible and full use of the policy of Sichuan provincial committee and government's Comments on Vigorously Supporting the Development of Leading Enterprises to Accelerate the promotion of Agricultural Industrialized Management. It should also adhere to the principle of "the state-owned, collective and private enterprises work together, and the capable ones lead and leading ones get supports". As to cultivating the leading enterprises, according to the model of Enterprises + Bases + Farmers, it should vigorously cultivate and introduce a number of leading enterprises with strong economic strength, high scientific and technological content as well as wide driving and radiation role to participate in the base construction, so as to promote the leading enterprises and farmers to form a relatively stable purchase-sales relationship, and drive the "order fruit industry" to develop in the direction of scalization and standardization. The greatest supports should be given to the regulatory operation of profession cooperative organizations, keeping a robust growth, the technical training and scientific guidance, the supply of agricultural materials and the fight for the right of export qualification. When conditions are mature, it can integrate resources and establish the kiwifruit industry group, and change the integration of base production, scientific research and development, product processing and marketing into the group's internal functions, so this will help the industry's overall coordinated promotion, change the acts of government into business practices, and enhance 
the decision-making power of enterprises, thereby improving farmers' ability to resist natural and market risks.

\subsection{Integrating Forces and Enhancing Publicity to Vigorously Implement the Brand Strategy}

Under the market economy, the brand strategy is the important means of agricultural industrialized management. Cangxi County should take advantage of its ecology, variety, popularity and other advantages to integrate various publicity powers of production, supply and sales, thus to create the brand of Cangxi red flesh kiwifruit. First, it should focus on "one red and one green", that is, to produce green food by taking the red flesh kiwifruit as its advantage, so as to cultivate the fresh Hongyang kiwifruit and a series of processing brands which are large-scale and high-grade. Second, it should produce high-quality fresh Hongyang kiwifruit and develop high-quality Hongyang kiwifruit processing products, thus to constantly introduce competitive products to the market to strength the products' competitiveness. Third, it should make use of market means to increase the publicity of brand Cangxi red flesh kiwifruit, and through various international conferences, the National Agricultural Fair, the daughter festival and pear flower festival held in the city and other activities, it should hold the kiwifruit-based ecological travelling and sightseeing activities, and by using modern media means, make comprehensive and multi-level publicity of the Cangxi red flesh kiwifruit industry, thereby improving the reputation at home and abroad. Fourth, it should change its marketing strategies, improve the marketing levels, create the market vectors as well as conduct the regulation and control operation. It should strengthen international cooperation, targeting its vision at the Southeast Asian and European markets, while in China, it should occupy Guangzhou, Beijing, Shanghai and other big cities, and the products must enter the supermarkets, hotels and conference business centers, besides, it should strengthen the marketing team building, and establish the kiwifruit industry wholesale markets and storages at three levels of city, county and town, so as to actively develop the modern marketing industry and implement online marketing, direct-supply marketing and chain marketing. Therefore, this can make Hongyang kiwifruit products occupy a great market share, thereby promoting the development of bases.

\subsection{Increasing the Protection of the Origin of Hongyang Kiwifruit}

Cangxi County is the origin of Hongyang kiwifruit, and its variety characteristics and origin advantages are unique. It has won the market opportunities with the "red flesh" kiwifruit brand, so that the "red flesh" kiwifruit and its processing products rapidly occupied the domestic and foreign markets. As to the protection measures, in addition to protecting the trademark and patent, it should also enhance the protection of the intellectual property of Hongyang kiwifruit, and strength the management research on seedling outflow and professional technical personnel outflow.

\section{Conclusion}

To sum up, Cangxi Hongyang kiwifruit has high planting benefits, and the natural ecological conditions for the industry development are superior, besides, Cangxi has many years of planting experience as well as the stable the scientific and technological team. Cangxi Hongyang kiwifruit has significant comparative advantages from both the domestic and foreign perspectives, and it has a great potential of industrialization. As long as the county grabs the major conflicts of resource integration, base construction, the introduction and cultivation of leading enterprises as well as the market development and marketing, and increases the strength on organization and support, the Hongyang kiwifruit industry in Cangxi County will be able to keep a robust growth, and play an important role in increasing farmers' income, promoting the adjustment of agricultural structure and advancing the progress in countryside.

\section{References}

Chen, Wk \& Tan J. (2003). Agricultural industrialization. Sichuan science and technology press.

Cui, Xiang. (2009). Northwest gardening. Northwest gardening, 08.

Lan, XQ \& Lan, XS. (2009). Kiwi growing economic analysis in XiuWen county. Agricultural extension service, 26(6):155-156.

Lv, JH, Lu, JL, \& Chen, CX. (2010). Fine early-maturing kiwi fruit varieties Characteristic agriculture development mode and reviewed. Anhui agricultural science, 38(11).

Peng, XY \& Jin, FZ. (2006). Theory of characteristic agriculture and development models theoretical connotation. Xianghu BBS, 20(5)-2.

Xue, Liang. (2008). Agricultural Modernization Ro ad with Chinese Characteristics from the View of Scale Operation in Agriculture. Issues in Agricultural Economy (Monthly), No16 /2008. 
Table 1. Cost Structures of Four Planting Patterns of Grain and Oil Crops

\begin{tabular}{|c|c|c|c|c|c|c|c|c|}
\hline Pattern & \multicolumn{2}{|c|}{$\begin{array}{c}\text { Pattern 1 } \\
\text { Rice + Wheat }\end{array}$} & $\begin{array}{c}\text { Pattern 2 } \\
\text { Wheat + Rice + Sweet } \\
\text { Potato }\end{array}$ & \multicolumn{2}{|c|}{$\begin{array}{c}\text { Pattern 3 } \\
\text { Wheat + Corn + Peanut }\end{array}$} & \multicolumn{2}{c|}{$\begin{array}{c}\text { Pattern } 4 \\
\text { Rice + Rape }\end{array}$} \\
\hline & $\begin{array}{c}\text { Absolute } \\
\text { number }\end{array}$ & Proportion & $\begin{array}{c}\text { Absolute } \\
\text { number }\end{array}$ & Proportion & $\begin{array}{c}\text { Absolute } \\
\text { number }\end{array}$ & Proportion & $\begin{array}{c}\text { Absolute } \\
\text { number }\end{array}$ & Proportion \\
\hline $\begin{array}{c}\text { Labor } \\
\text { Cost }\end{array}$ & 14,100 & $62 \%$ & 19,050 & $71 \%$ & 21,450 & $67 \%$ & 13,950 & $62 \%$ \\
\hline $\begin{array}{c}\text { Material } \\
\text { Cost }\end{array}$ & 8,700 & $38 \%$ & 7,770 & $29 \%$ & 10,380 & $33 \%$ & 8,625 & $38 \%$ \\
\hline $\begin{array}{c}\text { Total } \\
\text { Cost }\end{array}$ & 22,800 & $100 \%$ & 26,820 & $100 \%$ & 31,830 & $100 \%$ & 22,575 & $100 \%$ \\
\hline
\end{tabular}

Unit: yuan $/ \mathrm{hm}^{2}$

Remark: (1) The labor costs all includes planting, fertilizing, weeding, pest control, harvesting, drying and other costs, of which the labor cost of rice is 7,800 yuan $/ \mathrm{hm}^{2}$, the wheat is $6,300 \mathrm{yuan} / \mathrm{hm}^{2}$, the corn is $7,500 \mathrm{yuan} / \mathrm{hm}^{2}$, the sweet potato is 5,250 yuan $/ \mathrm{hm}^{2}$, the peanut is $7,650 \mathrm{yuan} / \mathrm{hm}^{2}$, and the rape is $6,150 \mathrm{yuan} / \mathrm{hm}^{2}$. (2) The material costs all include manure, chemical fertilizers, pesticides, agricultural film, watering, pactrometer and other costs, of which the material cost of the rice is $5,400 \mathrm{yuan} / \mathrm{hm}^{2}$, the wheat is $3,300 \mathrm{yuan} / \mathrm{hm}^{2}$, the corn is $3,525 \mathrm{yuan} / \mathrm{hm}^{2}$, the sweet potato is $945 \mathrm{yuan} / \mathrm{hm}^{2}$, the peanut is $3,550 \mathrm{yuan} / \mathrm{hm}^{2}$, and the rape is $3,225 \mathrm{yuan} / \mathrm{hm}$.

It can be found from the above analysis that: (1) Among Hongyang kiwifruit, Cangxi pear and the four planting patterns, the production cost of Hongyang kiwifruit is the highest. (2) The production cost of "wheat + corn + peanut" pattern is higher than that of Cangxi pear and the other three planting patterns, just lower than that of Hongyang kiwifruit.

Table 2. Comparison of Costs and Benefits of Hongyang Kiwifruit, Pear and Four Planting Patterns

\begin{tabular}{|c|c|c|c|c|c|c|c|c|c|c|c|c|}
\hline \multicolumn{2}{|c|}{$\begin{array}{l}\text { Variety or Planting } \\
\text { Pattern }\end{array}$} & $\begin{array}{l}\text { Produ- } \\
\text { ction } \\
\left(\mathrm{kg} / \mathrm{hm}^{2}\right)\end{array}$ & $\begin{array}{l}\text { Unit } \\
\text { Price } \\
\text { (yuan/ } \\
\text { kg) }\end{array}$ & \multicolumn{2}{|c|}{$\begin{array}{c}\text { Income } \\
\left(\text { yuan } / \mathrm{hm}^{2}\right)\end{array}$} & \multicolumn{2}{|c|}{$\begin{array}{l}\text { Labor Cost } \\
(\text { yuan/hm²) }\end{array}$} & \multicolumn{2}{|c|}{$\begin{array}{l}\text { Material Cost } \\
\left(\text { yuan } / \mathrm{hm}^{2}\right)\end{array}$} & $\begin{array}{c}\text { Cost } \\
\text { Amortiza- } \\
\text { tion before } \\
\text { Production } \\
\left(\text { yuan } / \mathrm{hm}^{2}\right)\end{array}$ & $\begin{array}{c}\text { Total } \\
\text { Production } \\
\text { Cost } \\
\text { (yuan } / \mathrm{hm}^{2} \text { ) }\end{array}$ & $\begin{array}{c}\text { Profit } \\
\text { (yuan/h } \\
\mathrm{m}^{2} \text { ) }\end{array}$ \\
\hline \multicolumn{2}{|c|}{ Hongyang Kiwifruit } & 15,000 & 11.00 & \multicolumn{2}{|c|}{165,000} & \multicolumn{2}{|c|}{16,500} & \multicolumn{2}{|c|}{17,550} & $6,438.8$ & $40,488.8$ & $124,511.2$ \\
\hline \multicolumn{2}{|c|}{ Cangxi Pear } & 37,500 & 1.00 & \multicolumn{2}{|c|}{37,500} & \multicolumn{2}{|c|}{12,000} & \multicolumn{2}{|c|}{14,550} & $4,357.5$ & $30,907.5$ & $6,592.5$ \\
\hline \multirow{2}{*}{ Pattern 1} & \multirow{2}{*}{$\begin{array}{l}\text { Rice+ } \\
\text { Wheat }\end{array}$} & 9,375 & 1.9 & $17,812.5$ & \multirow[b]{2}{*}{$26,782.5$} & 7,800 & \multirow{2}{*}{14,100} & 5,400 & & \multirow[b]{2}{*}{0} & \multirow{2}{*}{22,800} & \multirow{2}{*}{$3,982.5$} \\
\hline & & 4,875 & 1.84 & 8,970 & & 6,300 & & 3,300 & 8,700 & & & \\
\hline \multirow{3}{*}{ Pattern 2} & \multirow{3}{*}{$\begin{array}{c}\text { Wheat }+ \\
\text { Corn } \\
+ \text { Sweet } \\
\text { Potato } \\
\end{array}$} & 2,625 & 1.84 & 4,830 & \multirow{3}{*}{18,105} & 6,300 & \multirow{3}{*}{19,050} & 3,300 & \multirow{3}{*}{7,770} & \multirow{3}{*}{ 0 } & \multirow{3}{*}{26,820} & \multirow{3}{*}{$-8,715$} \\
\hline & & 6,750 & 1.7 & 11,475 & & 7,500 & & 3,525 & & & & \\
\hline & & 4,500 & 0.4 & 1,800 & & 5,250 & & 945 & & & & \\
\hline \multirow{3}{*}{ Pattern 3} & \multirow{3}{*}{$\begin{array}{l}\text { Wheat } \\
+ \text { Corn } \\
+ \text { Peanut }\end{array}$} & 2,625 & 1.84 & 4,830 & \multirow{3}{*}{26,205} & 6,300 & \multirow{3}{*}{21,450} & 3,300 & \multirow{3}{*}{10,380} & \multirow{3}{*}{$\mathbf{0}$} & \multirow{3}{*}{31,830} & \multirow{3}{*}{$-5,625$} \\
\hline & & 6,750 & 1.7 & 11,475 & & 7,500 & & 3,525 & & & & \\
\hline & & 2,250 & 4.4 & 9,900 & & 7,650 & & 3,555 & & & & \\
\hline \multirow{2}{*}{ Pattern 4} & Rice+ & 9,750 & 1.9 & 18,525 & & 7,800 & & 5,400 & & & & \\
\hline & Rape & 2,250 & 3.6 & 8,100 & 26,625 & 6,150 & 13,950 & 3,225 & 8,625 & 0 & 22,575 & 4,050 \\
\hline
\end{tabular}

